\title{
SHIP PASSING THROUGH STRAITS
}

\author{
Vytautas Paulauskas \\ Shipping Department, Klaipéda University, H. Manto g. 84, LT-92294 Klaipéda, Lithuania \\ E-mail:donatasp@takas.lt
}

\author{
Received 10 January 2010; accepted 15 November 2010
}

\begin{abstract}
All ports and a number of waterways have straits to optimize investments in developing such systems reaching the maximum results with minimum expenditures. New high accuracy port navigational systems have a possibility of high precision ship positioning and any time should guarantee shipping safety in port waters which makes a good basis for the optimization of port development. A new type of ships with good steering equipment and ship steering knowledge and methods in combination with very high accuracy port navigational systems such as E-Sea Fix and horizontal/vertical port channel bottom scanning possibilities guaranteeing real port water bottom conditions could stimulate dramatically increasing ship sizes at the port entrance in case of guaranteed shipping safety. With reference to straits, a theoretical study and experimental results received by simulators and real ships under much the same conditions have delivered a new knowledge of the limit of big ship sailing in straits and the possibilities of increasing ship size under similar sailing conditions. The Klaipeda strait is taken as the case study for practical testing. The paper presents the results, conclusions and recommendations of a theoretical and practical study for the ships of an increased size at strait ports.
\end{abstract}

Keywords: ship sailing, channel width, ship steering, navigational safety.

\section{Introduction}

Port channels are a part of port infrastructure that must ensure safety for the biggest calculated ship. Channel development and improvement request large investments which seem to be very important issues of maximizing the possibilities of using channels. At the same time, traditions and a lack of port administration/pilots' knowledge concerning the possibilities of steering new ships frequently impose limits regarding parameters of the ships entering the port. Consequently, similar decisions made by port administration may decrease the competitiveness of port staff (Paulauskas 2004, 2009; Paulauskas and Bentzen 2008; Thiers and Janssens 1998; Köse et al. 2003; Ors and Yilmaz 2004; Su and Wang 2009; Başar 2010; Hess and Hess 2010, etc.).

Detailed studies on ships passing through straits are very important to maximize the use of channels optimizing channel development and improvement investments in case of ensuring navigational safety.

Ship bridge visual simulators along with experiments on real ships assist in checking the quality of theoretical studies and improvements in the bottlenecks of navigational channels. At the same time, ship bridge visual simulators are used mainly for training navigators and pilots and show real possibilities of channels.
Mathematical models used in simulators can assist with evaluating a number of sailing ships and environmental parameters and can assess a real situation in case of good preparation identifying up to $90-95 \%$ of real conditions.

More officially agreed ship models are frequently applied in simulators which therefore makes additional difficulties and not always shows a more realistic picture (SimFlex Navigator Simulator 2009).

Simulators simultaneously can be used for additional purposes such us investigations into navigational pass, ship mooring and unmooring limitations, ship clearance situation in particular channels, evaluation of accident probability on statistical basis etc.

Studies on navigational ship pass and received limitations in case of incorrectly implemented internal and external conditions can be successfully used for increasing the competitiveness of ports and waterways and for ensuring navigational safety (Paulauskas et al. 2009).

The Klaipeda strait and theoretically biggest possible POST-PANAMAX container vessel 6800 TEU having the length of $347 \mathrm{~m}$, width of $42.8 \mathrm{~m}$ and draft of $12.5 \mathrm{~m}$ were taken as examples for the case study.

The conditions accepted within the simulator should be double or triple checked considering technical (real ships) and expert evaluation systems (navigators, pilots). Next, the results obtained after filtration 
can be used for navigational ship pass, the evaluation of mooring and unmooring limitation conditions and other studies.

\section{Mathematical Models for Studying Straits}

Mathematical models or complexes of models used for studying navigational ship pass through channels should include:

- characteristics of ship manoeuvrability;

- shallow water influence on the ship;

- influence of environmental conditions on the ship and on navigation conditions;

- channel slops or quay walls clause to channel characteristics;

- fender characteristics (absorb energy, reaction forces etc.);

- additional characteristics of ship equipment;

- other additional parameters that can have an influence on the above mentioned situations such as tugs, other target ships etc.

The above mentioned parameters can be expressed as follows (Çakmak and Ersöz 2007):

$$
\begin{aligned}
& \lim \Rightarrow \omega, \beta, v, S, \ldots . \\
& a_{i} \in F,
\end{aligned}
$$

where: $a_{i}$ - individual influential parameters; $F$ forces as a result of individual parameters of influence; $\omega, \beta, v, S \ldots .$. - ship kinematics and dynamic parameters as a result of internal and external forces and influential moments.

For calculating the above mentioned parameters, the method of using the Laplace operator and superposition calculation is possible. According to the superposition method, all influence factors can be calculated as separate influences and summarized at the end.

The Laplace operator can be shown in the following way (Fig. 1).

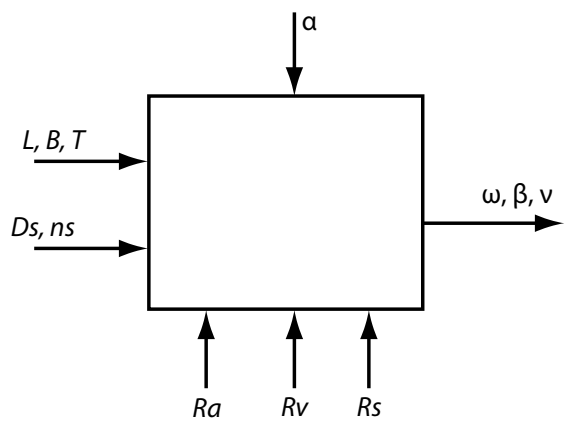

Fig. 1. The Laplace operator for calculating maneuverability characteristics of the ship and evaluation of ship passing

Fig. 1 includes the main conditions for ships and environment having influence on the maneuverability characteristics of ships: $\alpha$ - ruder turn angle; $L, B, T-$ geometrical characteristics (length, width, draft etc.) of ships; $D_{s}$ - the diameter of ship propeller; $n_{s}$ - the turning velocity of propellers; $R_{a}$ - aerodynamic loads; $R_{V}-$ waves forces; $R_{S}$ - forces of the influence of shallow waters; $v$ - ship speed; $\beta$ - ship drift angle; $\omega$ - the turning velocity of the ship.

Ship influence on the quay wall and quay wall furniture (fenders) or other objects in case of too narrow (navigational) passes and possible contacts between ship and quay wall or other waterfront structure could be calculated on the basis of kinetic energy (Paulauskas 2004):

$$
E=m \cdot v_{y}^{2} / 2
$$

where: $m$ - the mass of the ship, including added water mass; $v_{y}$ - ship's contact speed with the quay wall or other obstacle (Fig. 2).

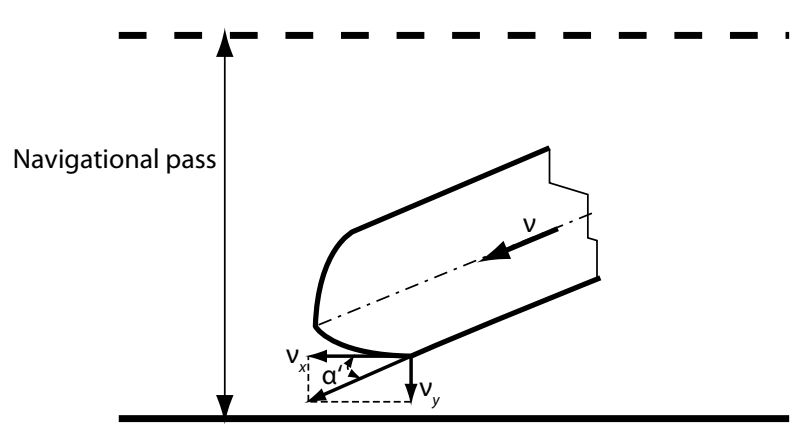

Fig. 2. Navigational pass of ships and ship's contact with the quay wall or other obstacle

The contact speed of ship $v_{y}$ can be calculated as:

$$
v_{y}=v \cdot \sin \alpha^{\prime}
$$

where: $\alpha^{\prime}-$ ship course to the quay wall (mooring) angle.

The mass of the ship must be calculated along with the added water mass which in many records is used as mass (Paulauskas et al. 2008) when a ship moves to $Y$ direction or the total added water mass (Fig. 3).

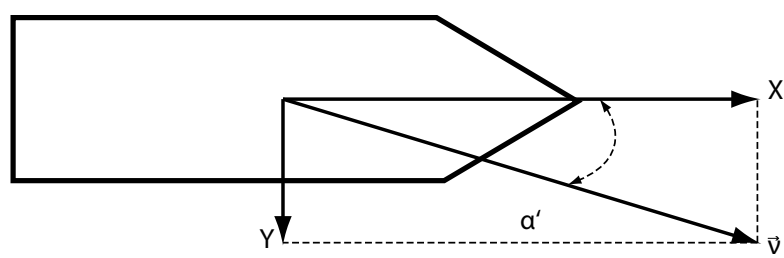

Fig. 3. The mooring direction and speed vector of the ship

In case of ship moving direction $\vec{v}$ as shown on Fig. 3, the total added water mass should be calculated as:

$$
\lambda_{\omega}=\lambda_{11} \cdot \cos \alpha^{\prime}+\lambda_{22} \cdot \sin \alpha^{\prime}
$$

where: $\lambda_{11}$ - the added water mass in case of the ship following $X$ direction, can be calculated as:

$$
\lambda_{11}=V \cdot k_{11}
$$


$\lambda_{22}$ - the added water mass in case of the ship following $Y$ direction, can be calculated as:

$$
\lambda_{22}=V \cdot k_{22} \text {. }
$$

In formulas (5) and (6), $V$ - ship displacement; $k_{11}$ - the coefficient of the added water mass in case of the ship moving towards $X$ direction (in case of the ship touching a quay wall, $k_{11}$ can be accepted from 0.06 to $0.08) ; k_{22}$ - the coefficient of the added water mass in case the ship moving towards $Y$ direction (considering the above introduced conditions, $k_{22}$ can be accepted from 0.7 to 0.8 ).

For the full evolution of energy that should be absorbed by fenders or other obstacle (BS 6349-1:2000; BS 6349-4:2000), the below formula (for fenders) (Guidelines for the Design... 2002; Criteria for Movements... 1995; Recommendations of the Committee... 2000, 2006) could be used:

$$
E_{F}=E \cdot C_{1} \cdot C_{2} \cdot C_{3} \cdot C_{4},
$$

where: $C_{1}$ - eccentricity factor can be accepted approximately from 0.5 (long objects such as long quay walls, channel slops etc.) to 0.7 (dolphins, shallow water etc.); $C_{2}$ - the virtual mass factor can be calculated using the above discussed methods or accepted from approximately the average result of 1.75 according to Vasco Costa recommendations (Guidelines for the Design... 2002; Criteria for Movements... 1995); $C_{3}$ - softness factor for hard structures such as quay walls, rocks, hard channels, slops etc. can be accepted as 1.0 and for soft channels and slops such as clay, sand with organic material etc. as $0.7-0.8 ; C_{4}-$ configuration or a cushion factor in many cases can be agreed approximately as 1.0.

Shallow water influence on ship moving and maneuverability characteristics and ship draft can be calculated according to the methodology presented in (Paulauskas 1998):

$$
\begin{aligned}
& \omega_{(s)}=k_{\omega} \cdot \omega ; \\
& v_{(s)}=v_{0} \cdot \sqrt{\frac{1+k_{11}^{\prime}}{1+k_{11}}} ; \\
& \sin \beta_{(s)}=\frac{L \cdot B \cdot \omega_{(s)}}{v_{(s)}},
\end{aligned}
$$

where: $\omega_{(S)}$ - turning velocity on shallow water; $\omega-$ turning velocity on deep water; $k_{\omega}$ - turning velocity coefficient as the effect of shallow water; $v_{0}$ - initial speed on deep water; $v_{(s)}$ - initial speed on shallow water; $k_{11}$ - the added water mass coefficient on shallow water; $\beta_{(s)}$-drift angle on shallow water.

Trajectory in coordinates $X_{0}$ and $Y_{0}$ can be calculated as:

$$
\begin{aligned}
& X_{0 i}=\int_{0}^{t} v \cdot \cos \left(\int_{0}^{t} \omega_{i} d t-\beta_{i}\right) d t ; \\
& Y_{0 i}=\int_{0}^{t} v \cdot \sin \left(\int_{0}^{t} \omega_{i} d t-\beta_{i}\right) d t .
\end{aligned}
$$

The navigational pass of the ship in straits can be calculated as:

$$
B_{a}^{\prime}=L \cdot \sin \beta+B \cdot \cos \beta+P^{\prime} \cdot \sigma_{y}+L \cdot \sin \Delta K+b_{n},
$$

where: $P^{\prime}$ - probability coefficient for navigational purposes in case of probability not less than $95 \%, P^{\prime}$ can be accepted not less than 2.5; $\sigma_{y}$ - the observation of ship position in case of using DGPS (Differential Global Position System), other navigation system (E-Sea Fix Navigation System 2003) or the aid of navigation, for example, headlines could be applied according to accuracy in a particular place under real conditions; $\Delta K$ - ship rolling angle around the ship course or planning trajectory; $b_{n}$ - additional navigation safety depends on the channel border or slop accuracy and counts about $(0.5-1.0) B$ in typical ports.

On the basis of the above presented methodology, the main ship moving parameters and navigational pass can be received.

For the filtration of the received data, Colman as well as other filters can be used which in fact reject the data that is probably less than agreed, for example, $20 \%$ of the total data in case if the amount of this information is large enough.

For filtration purposes, the variation coefficient using mathematical dispersion and data standards can be calculated as follows (Baublys 2003, 2007-2009; Bagdoniené 2008):

$$
e^{2}=\vartheta_{y}^{2}=S_{\varsigma}^{2},
$$

where: $e$ - average quadratic error; $S_{c}$ - data standard; $\vartheta_{y}$ - mathematical dispersion (density) calculated in the following way (Вентцель 1969):

$$
\vartheta_{y}^{2}=\frac{1}{n-1} \cdot \sum\left(B_{a(i)}^{\prime}-m_{y}\right)^{2},
$$

where: $n$ - the number of ship runs; $B_{a(i)}^{\prime}$ - the width of particular navigation pass or, for example, the distance from channel middle (diametric) line (access) and ship mass centre; $m_{y}$ - mathematical waiting factor is calculated as:

$$
m_{y}=\frac{1}{n} \cdot \sum B_{a(i)}^{\prime} .
$$

Variation coefficient can be calculated on the basis of standard data and mathematical waiting factor:

$$
\delta=\frac{S_{\varsigma}}{m_{y}} .
$$

With reference to these formulas, a possibility of finding a pass as mathematical waiting factor $m_{y}$ and the spread of density around the central line of channel access can be observed (Fig. 4).

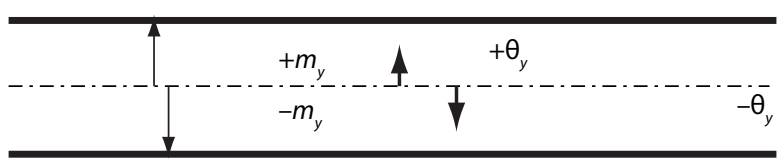

Fig. 4. A mathematical waiting factor of ship passing and dispersion 
On the basis of the theoretical method presented in this section, ship accident probability in narrow strait channels depending on ship and channel parameters and sailing conditions could be found (Paulauskas 2006). The probability of ship accident was evaluated via dispersion as follows:

$$
\begin{aligned}
& \Delta B=1.0 e ; P=63 \% ; \\
& \Delta B=2.5 e ; P=95 \% ; \\
& \Delta B=3.0 e ; P=99.9 \% .
\end{aligned}
$$

The probability of more than $99.9 \%$ in maritime navigation is very rare and mainly taken in calculations not less than $95 \%$ with a possibility of making additional control, for example under VTS (vessel traffic control).

\section{Practical Calculations and Testing Navigational Pass of the Ship}

Practical calculations of the navigational pass of ships in ports were taken as a basis for the case study conducted in the Klaipeda strait that accounts for entering large ships and their contacts with the fender systems of quay walls Figs 5-14. For the study on ship passing, POSTPANAMAX container vessels having the length of 347 $\mathrm{m}$, width of $42.8 \mathrm{~m}$ and draft of $12.5 \mathrm{~m}$ were applied. For the purposes of calculations, real channels having the width from $110 \mathrm{~m}$ to $120 \mathrm{~m}$, depth from 13.0 to $13.5 \mathrm{~m}$ were accepted as examples. For evaluation, full mission simulator SimFlex Navigator (2009) was used. The applied instrument has a possibility of receiving approximately 100 different sailing ships and environmental parameters. Some of the parameters established by SimFlex Navigator simulator are shown on Figs 5 and 6.

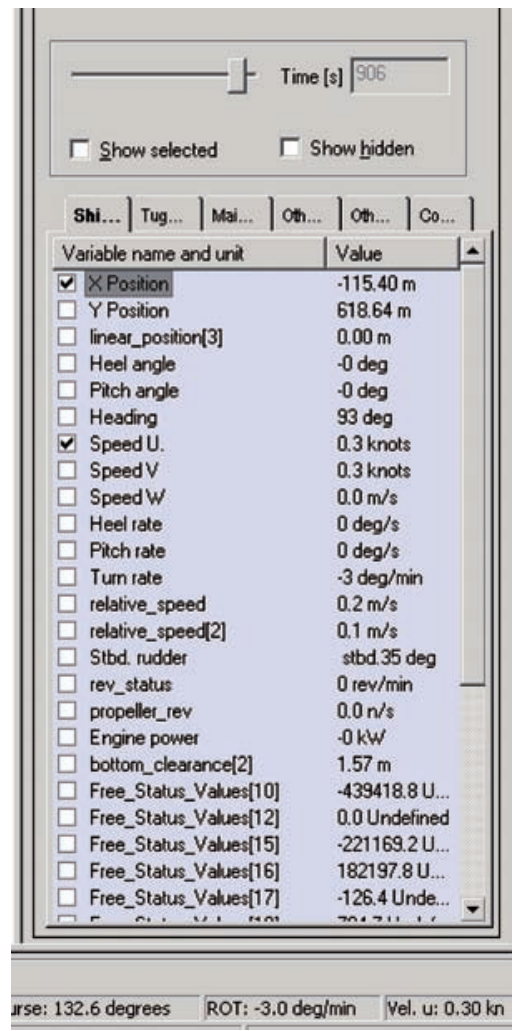

Fig. 5. Data on ship sailing received applying the simulator

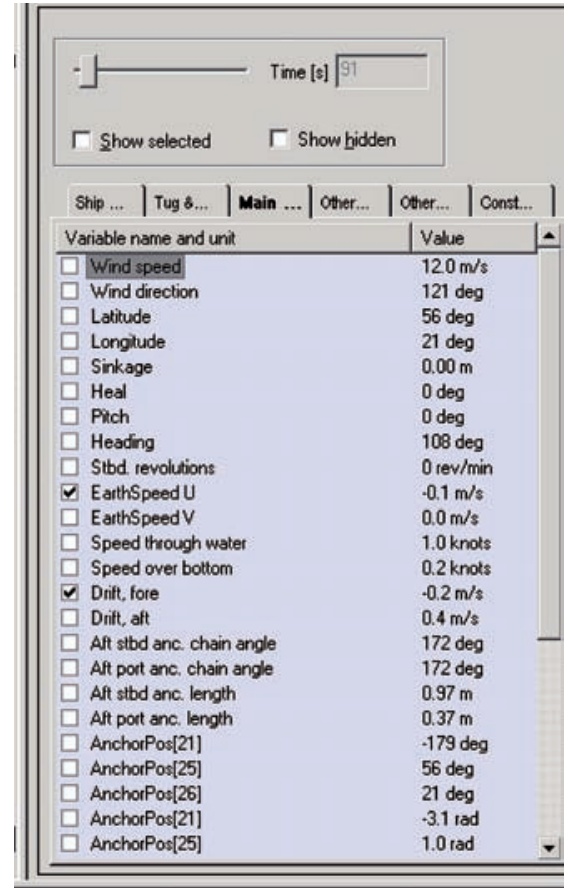

Fig. 6. Data on ship sailing and environmental factors received applying the simulator

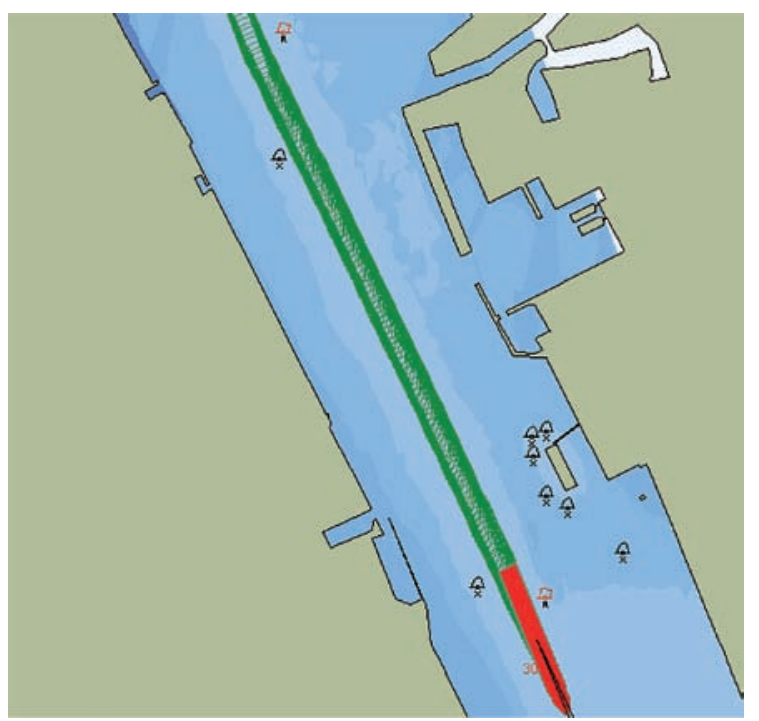

Fig. 7. POST-PANAMAX container vessel $(L=347 \mathrm{~m})$ passing through the narrow strait of width between 110 and $120 \mathrm{~m}$ (sailing parameters are presented in Fig. 8)

Ship sailing as well as forces and energy parameters in case of leaving the channel and touching quay walls or other obstacles were modelled on the quay walls supplied with fenders. Figs 9-12 show ships touching quay walls, the main forces and sailing parameters.

The results of an experimental study on drift angle $\beta$ and the rolling angle of ship moving $\Delta K$ in real ships and simulators as well as findings on the trends depending on the wind at a 90 degree angle and wind velocity for the POST-PANAMAX class of ships are presented in Figs 13 and 14. 


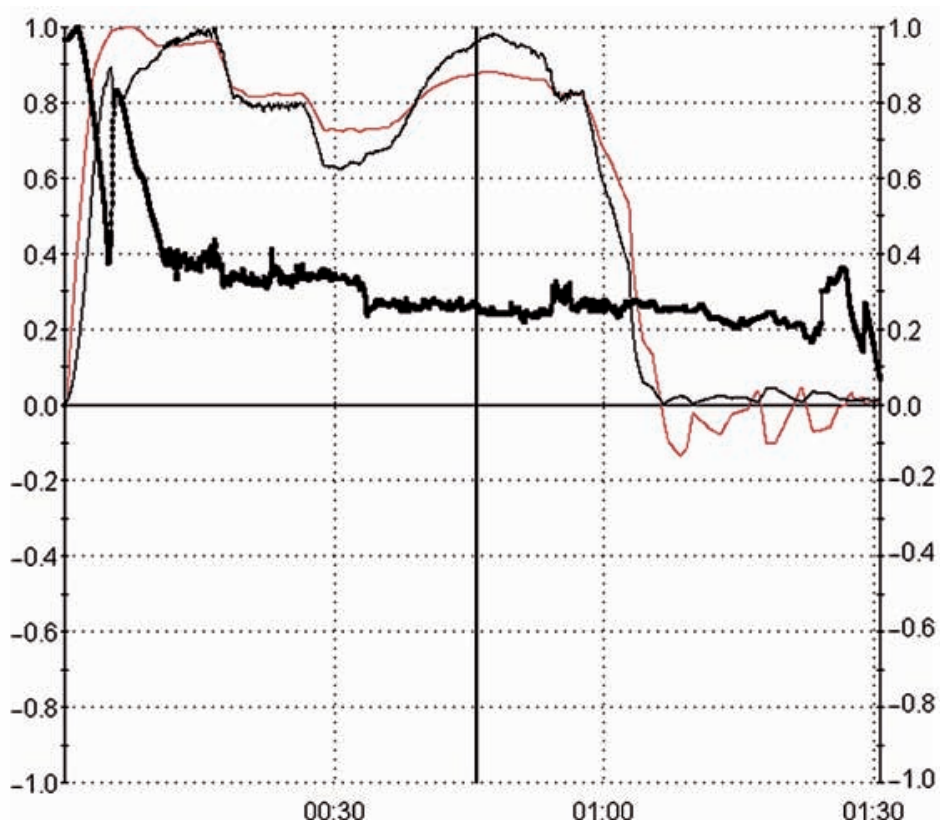

Fig. 8. Parameters of the vessel of POST-PANAMAX container crossing over a narrow strait (vertical line indicates ship position, see Fig. 7)

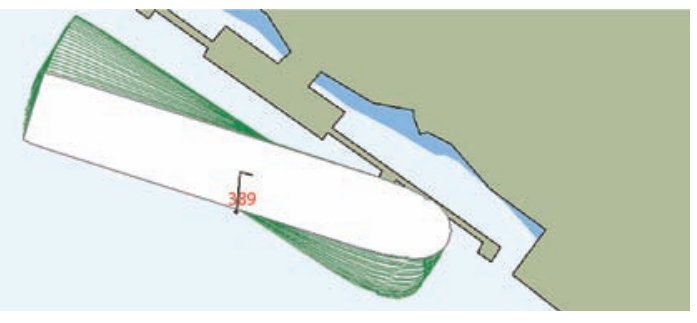

Fig. 9. The trajectory of PANAMAX type vessel ( $L=220 \mathrm{~m}$ ) leaving the channel and touching waterfront structure (sailing parameters are presented in Fig. 10)
On the basis of the received data presented in Fig. 13 and Fig. 14, a request of strait width for POST-PANAMAX container vessel depending on the wind at a 90 degree angle and wind velocity was calculated (Fig. 15).

On the basis of theoretical and test results, it can be concluded that necessary strait width for POST-PANAMAX vessels makes about $145-150 \mathrm{~m}$ in case of minimum limitation under hydro meteorological conditions. As an example, the Klaipeda internal strait has the width of $120 \mathrm{~m}$, and thus, in this case, POST-PANAMAX container vessels can entry the Klaipeda port under the ex-

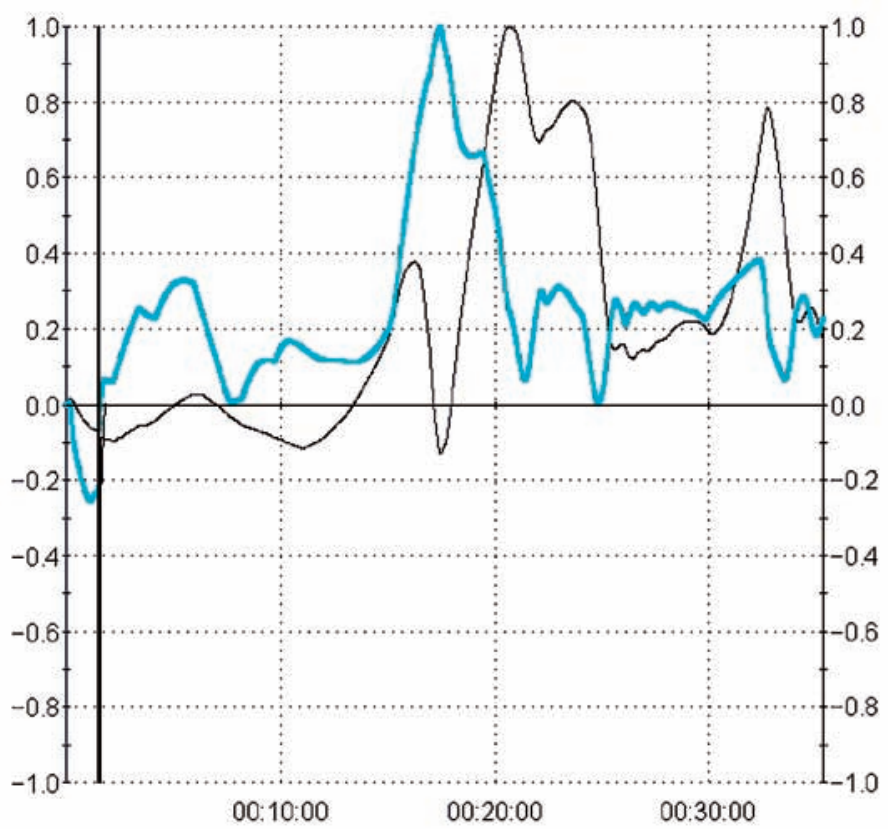

EarthSpeed U: $-0.1 \mathrm{~m} / \mathrm{s}$

Drift, fore: $-0.2 \mathrm{~m} / \mathrm{s}$

Fender_force - Land: $2047131.8 \mathrm{~N}$

Fig. 10. Parameters of PANAMAX vessel sailing through the narrow channel and touching waterfront structure (vertical line indicates ship position, see Fig. 9) 


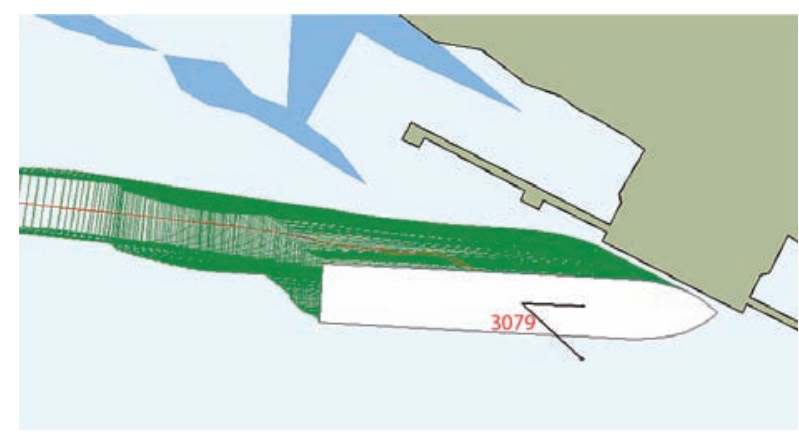

Fig.11. The trajectory of HANDYMAX vessel $(L=170 \mathrm{~m})$, sailing through the channel and touching waterfront structure (sailing parameters are presented in Fig. 12) isting infrastructure conditions with hydro meteorological limitations: wind velocity should be less than $8 \mathrm{~m} / \mathrm{s}$ from traverse directions, whereas taking into account changes in limitations and the same navigational safety level considering POST-PANAMAX container vessels, it is necessary to make additional dredging works to reach enough width and depth when approaching the inside channels.

Practical investigations into big bulk ships in ballast reveal that they have equal wind surface and sail to the same quay walls which means the use of the same port channels and turning basins. The received results have shown that theoretical calculations and simulations using a full mission simulator and the findings on real practical experience are equal and at the first stage of the study, it is possible to use the method of theoretical calculation presented in this article.

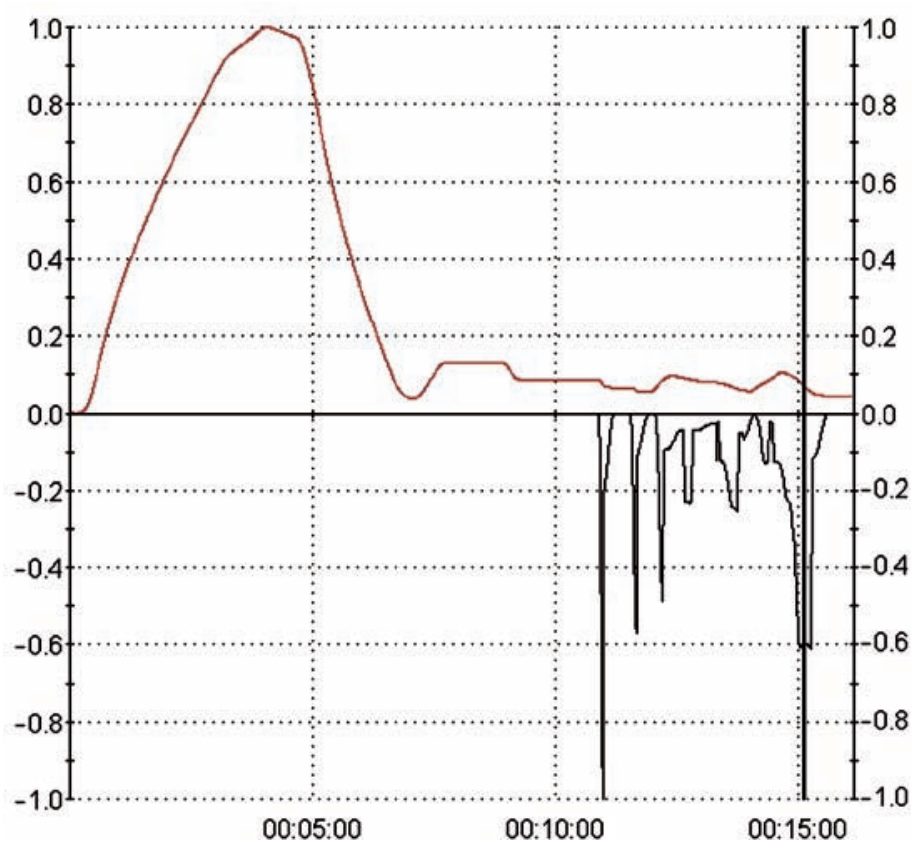

Fig. 12. Parameters of HANDYMAX vessel sailing through the narrow channel and touching waterfront structure (vertical line indicates ship position, see Fig. 11)

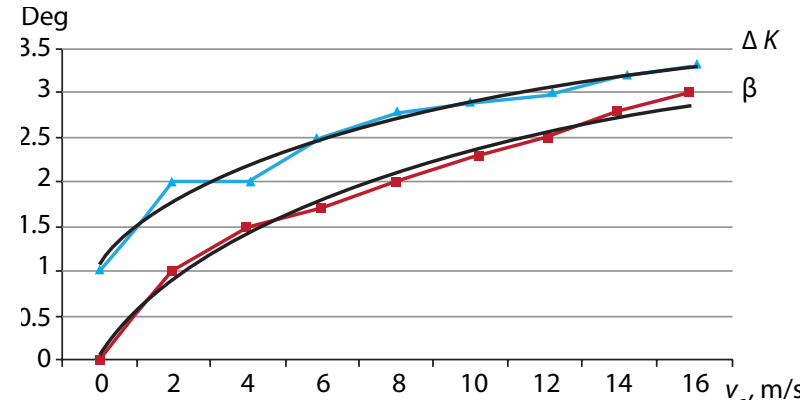

Fig. 13. Drift angle $\beta$ and the rolling angle of ship moving depending on the wind at a 90 degree angle and wind velocity for the POST-PANAMAX class of ships

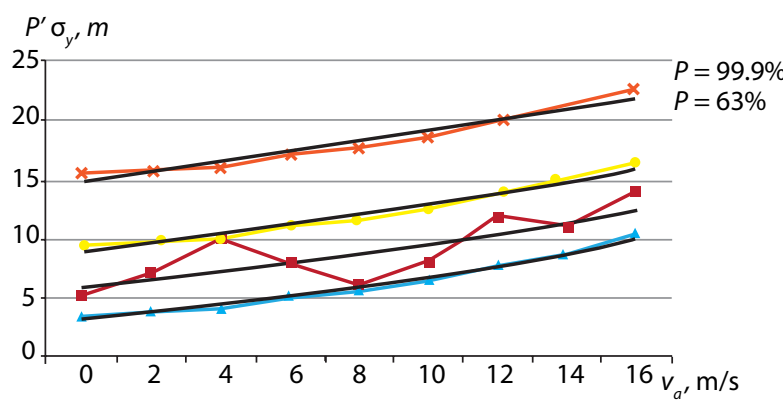

Fig. 14. The possible movements of the POST-PANAMAX class of ships from the central line of channel $P^{\prime} \sigma_{y}$ depending on the wind at a 90 degree angle and wind velocity in case of different probability $(P=63 \%$ and $P=99.9 \%)$ and experimental results (red line) 


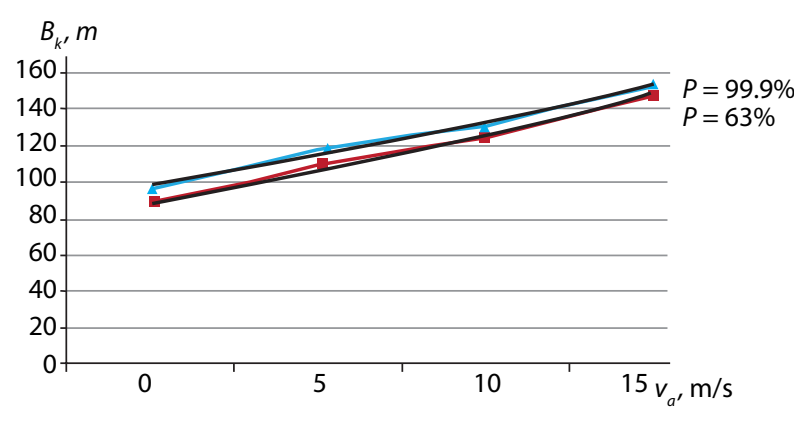

Fig. 15. A request of strait width for POST-PANAMAX container vessel depending on the wind at a 90 degree angle and wind velocity in case of different probability

$$
(P=63 \% \text { and } P=99.9 \%)
$$

\section{Conclusions}

1. The study on the possibilities of straits is important for finding the maximum of possible ships that can use particular channels and hydro meteorological limitations.

2. On the basis of theoretical studies and with reference to the experimental results of simulation tests involving big ships, it is possible to conclude that for POST-PANAMAX container vessels applied for the case study in the Klaipeda strait, minimum channel width should be not less than $125 \mathrm{~m}$ and wind velocity limitation should be accepted as $8-10 \mathrm{~m} / \mathrm{s}$.

3. For increasing the steering possibilities of large ships and minimizing channel width, it is necessary to use additional measures such as thrusters, tugs and high accuracy navigational systems, including Real Time Kinematic systems, for example E-Sea Fix etc., for increasing the accuracy of ship position and predicting other ship positions after some time in the future.

4. The methodology presented in this paper can assist with receiving correct results for the ships passing through straight channels.

\section{References}

Bagdoniene, D. 2008. Optimization of loading facilities at the terminal, Transport 23(2): 95-97. doi:10.3846/1648-4142.2008.23.95-97

Başar, E. 2010. Investigation into marine traffic and a risky area in the Turkish Straits system: Canakkale Strait, Transport 25(1): 5-10. doi:10.3846/transport.2010.01

Baublys, A. 2003. Transport system: models of development and forecast: monograph. Vilnius: Technika. 208 p.

Baublys, A. 2007. Probability models for assessing transport terminal operation, Transport 22(1): 3-8.

Baublys, A. 2008. Model for distribution of warehouses in the commercial network in optimising transportation of goods, Transport 23(1): 5-9. doi:10.3846/1648-4142.2008.23.5-9

Baublys, A. 2009. Principles for modelling technological processes in transport terminal, Transport 24(1): 5-13. doi:10.3846/1648-4142.2009.24.5-13

BS 6349-1:2000. British Standard. Maritime Structures. Code of Practice for General Criteria.

BS 6349-4:2000. British Standard. Maritime Structures. Code of Practice for Design of Fendering and Mooring Systems.
Çakmak, T.; Ersöz, F. 2007. Methodology recommendation for one-criterion transportation problems: CAKMAK method, Transport 22(3): 221-224.

Criteria for Movements of Moored Vessels in Harbours. 1995. PIANC.

E-Sea Fix Navigation System. 2003. Marimatech, Denmark, $120 \mathrm{p}$.

Guidelines for the Design of Fender Systems. 2002. PIANC.

Hess, S.; Hess, M. 2010. Predictable uncertainty about terminal operations in the sea, Transport 25(2): 148-154. doi:10.3846/transport.2010.18

Köse, E.; Başar, E.; Demirci, E.; Güneroğlu, A.; Erkebay, Ş. 2003. Simulation of marine traffic in Istanbul Strait, Simulation Modelling Practice and Theory 11(7-8): 597-608. doi:10.1016/j.simpat.2003.10.001

Ors, H.; Yilmaz, S. L. 2004. Oil transport in the Turkish Straits system, part II: a simulation of contamination in the Dardanelles strait, Energy Sources 26(2): 167-175. doi:10.1080/00908310490258542

Paulauskas, V. 1998. Laivo valdymas ypatingomis salygomis [Ship's steering in complicate conditions]. Klaipeda: Klaipedos universiteto leidykla. $164 \mathrm{p}$.

Paulauskas, V. 2004. Uostu terminaly planavimas [Ports terminal planning]. Klaipeda: Klaipedos universiteto leidykla. 382 p. (in Lithuanian).

Paulauskas, V. 2006. Navigational risk assessment of ships, Transport 21(1): 12-18.

Paulauskas, V. 2009. The safety of tankers and single point mooring during loading operations, Transport 24(1): 5457. doi:10.3846/1648-4142.2009.24.54-57

Paulauskas, V.; Bentzen, K. 2008. Sea motorways as a part of the logistics chain, Transport 23(3): 202-207. doi:10.3846/1648-4142.2008.23.202-207

Paulauskas, V.; Paulauskas, D.; Wijffels, J. 2008. Ships mooring in Complicated Conditions and possible solutions, in Proceedings of the 12th International Conference 'Transport means', 67-70.

Paulauskas, V.; Paulauskas, D.; Wijffels, J. 2009. Ship safety in open ports, Transport 24(2): 113-120. doi: 10.3846/1648-4142.2009.24.113-120

Recommendations of the Committee for Waterfront Structures - Harbours and Waterways (EAU 1996). 2000. 7th edition. Ernst \& Sohn. 628 p.

Recommendations of the Committee for Waterfront Structures - Harbours and Waterways (EAU 2004). 2006. 8th edition. Wiley. 660 p.

SimFlex Navigator Simulator. 2009. Force Technology, Denmark.

Su, T.-J.; Wang, P. 2009. Carrier's liability under international maritime conventions and the UNCITRAL draft convention on contracts for the international carriage of goods wholly or partly by sea, Transport 24(4): 345-351. doi:10.3846/1648-4142.2009.24.345-351

Thiers, G. F.; Janssens, G. K. 1998. A port simulation model as a performance decision instrument, Simulation 71(2): 117-125. doi:10.1177/003754979807100206

Вентцель, Е. С. 1969. Теория вероятности [Ventcel, E. S. Probability Theory]. Москва: Наука. 576 c. (in Russian). 